\title{
Mercados de trabajo y sub-utilización de la fuerza de trabajo en El Salvador
}

Carlos Briones

La idea básica que actua como un hilo conductor de las rellexiones desarrolladas en este arliculo, es que el verdadero problema ocupacional ha sido la débil capacidad de acumulación del sector "moderno" del aparalo produclivo. Esta incapacidad relativa se traduce en una débil capacidad de generación de empleo, que va produclendo acumulativamente un permanente "excedente estructural" de fuerza laboral.

Enfocar la problemática ocupacional desde la optica del "excedente estructural", supone adoptar como principales problemas la sub-utilización de la fuerza de Irabajo y la heterogenedidad de la "calidad" de los puestos de trabajo existenles en la estruclura ocupacional, es decir, supone transferir el toco de nuestra atención de una problemática fundamenlalmente coyuntural (desempleo) a una problemálica estructural (sub-empleo y bajos ingresos).

Consecuentemente con lo sefialado anteriormente se hace necesario el abandono de los análisis tradicionales que suponen la existencia de un mercado de trabajo único y la salarización total de la mano de obra, para adoplar un enfoque allernativo fundado en la segmentación de los mercados de trabajo.

Estos enfoques suponen, en oposición al paradigma neoclásico del mercado de trabajo, que los diferenciales en las remuneraciones de los trabajadores, la movilidad ocupacional entre los diferentes puestos de trabajo y las condiciones de vida de los trabajadores no se originan en las características individuales de los trabajadores sino más bien en la existencia de una fragmentación del mercado de trabajo en segmentación que se diferencia fundamentalmente por la forma que organizan el uso de la luerza de Irabajo. 
Esta segmentación tendría básicamenle dos fuentes, por un lado, se originarla en la existencia de un importante "excedente esınctural" de oferla de trabajo y por otra parte, sería la resultante de la diferenciación existente en la estructura empresarial en relación a los niveles de capilal por trabajador, la estabilidad de la demanda de los diferenles productos y el poder de mercado de cada empresa. ${ }^{1}$

La existencia de un "excedente estructural de mano de obra" comribuirla al desarrollo de la heterogeneidad de la estructura ocupacional al obligar a los trabajadores desfavorecidos a desarrollar un despliegue activo de estrategias de inserción en la estructura económica.

La polarización de la eslnuctura empresarial en dos grandes segmentos: gran empresa oligopólica y pequeha empresa concurrencial, segmentarla los mercados de trabajo al dilerenciar los puestos de trabajo en relación a la estabilidad del empleo, condiciones laborales y niveles de remuneración.

En el mercado laboral urbano de una economla sub-desarrollada como la nuestra, la interacción de los factores antes mencionados daria origen a una doble segmentación. Por un lado tendrlamos la segmentación clásica de mercados primarios y mercados secundarios, y por otra parte tendriamos una segmentación más amplia de la estructura ocupacional en "sector formal" y "sector irformal".

En general en el segmemto primario y el sector formal se ubicarian las ocupaciones estables, con buenas condiciones de trabajo y mejor remuneradas; en cambio, el segmento secundario y el sector informal conformarla el conjunto de las ocupaciones peor remuneradas, con precarias condiciones de trabajo, con alta inestabilidad en el empleo y alta subutilización de la fuerza de trabajo.

La verificación de las hipótesis de la segmentación constituye un paso previo para el replanteamiento de la política económica en el área laboral, ya que de comprobarse que la sub-utilización y las bajas remuneraclones conlienen su origen en la segmentación de la esinuctura ocupacional, las polilicas de empleo deberian abandonar el énfasis puesto en la simple reducción de la desocupación para centrar su acción en la "modemización - transiormación" de las estructuras ocupacionales con el objetlvo explícilo de reducir el sub-empleo y promover el mejoramiento det blenestar material de los trabajadores desfavorecidos. Dicho de otra forma, el objetivo no sera simplemente el de mantener una reducida lasa de desocupación abierta, sino el de crear y "re-crear" puestos de trabajo estables y productivos.

En este sentido nuestro trabajo partirá de una breve evaluación de la problemática ocupacional para posleriormente tratar de evidenciar la 
existencia de la segmentación de la estruclura ocupacional de acuerdo a los elementos antes mencionados.

La sub-utllización de la fuerza de trabajo. Evaluación del perlodo 19781985*

La sub-utilización de la capacidad productiva de los recursos humanos con que cuenta un país, puede asumir dos lormas: por una parte las personas con edad para trabajar y con deseos de realizar alguna aclividad producliva pueden enconirarse totalmente fuera de la estructura ocupacional y por olra parte las personas pueden, en contra de su voluntad, insertarse en la eslructura productiva solamente en forma parcial y/o inestable. La primera situación define al desempleo abierto y la segunda al subempleo.

Al respecto puede decirse que el desempleo es una situación originada fundamentalmente en un atascamiento de la dinámica de crecimiento del sector "moderno" o "formal" que se traduce generalmente en una expulsión temporal de mano de obra. En cambio, el sub-empieo sehalarla la incapacidad de ese mismo seclor, para crear suficienles puestos de trabajo que absorban en forma productiva a una creciente oferta de fuerza laboral.

Históricamente en El Salvador la magnitud del desempleo abierto no habla representado un serio problema, debido a que nunca habia sobrepasado una cilra de dos dígitos, sin embargo, a partir del comienzo de esta década, la convergencia de la aguerra, la declinación de la actividad económica interna y la desfavorable evolución del comercio mundial, configuraron un cuadro recesivo que coloco' de golpe al pais dentro del grupo de paises latinoamericanos de alta desocupación, es decir aquellos con lasas de desempleo abierto igual o superior al $10 \%$.

En tal sentido puede decirse que el lenómeno de corto plazo más relevante en el perlodo 1978-1985 ha sido el brutal aumento del desempleo abierto, ya que de acuerdo al cuadro resumen de las condiciones ocupacionales (cuadro No. 1) la población desocupada se multiplica en aproximadamente 3.5 veces, aumentando en alrededor de 200.000 personas? ${ }^{2}$.

En términos relativos el desempleo abierto ha mostrado una tendencia explosiva de crecimienlo en relación a cualquiera de los otros indicadores de la situación ocupacional.

Asi mientras la población de más de 10 años de edad únicamente se ha incrementado en $11.6 \%$ en relación a 1978 , el total de la población que se declara abiertamenle desempleada lo ha hecho en aproximadamente 253. $8 \%$. Aumenlos similares solamente se observan en el indicador de 


\section{EL SALVADOR: CONDICIONES OCUPACIONALES DE LA POBLACION EN EDAD DE TRABAJAR}

\begin{tabular}{|c|c|c|c|c|c|c|}
\hline & \multicolumn{3}{|c|}{1978} & \multicolumn{3}{|c|}{1808} \\
\hline & UREANO & AURAL & TOTAL & UคBANO & RURAL & TOTAL \\
\hline $\begin{array}{l}\text { Total población } \\
\text { (10 anosy más de } \\
\text { odad) }\end{array}$ & $1,336,599$ & $1.658,179$ & $2,995,770$ & $1,685,577$ & $1,648,674$ & $3,345,251$ \\
\hline $\begin{array}{l}\text { Poblacion Economi- } \\
\text { camente Acliva (ocu- } \\
\text { pados + desocupados }\end{array}$ & 701,846 & 817,508 & $1,518,454$ & 808,025 & 747,384 & $1,053,400$ \\
\hline Total Ocupados & 673,156 & 767,086 & $1,440,242$ & 746,242 & 627,053 & $1,373,140$ \\
\hline - Oajpadín plena* & 472,607 & 305,420 & 778,257 & 467,712 & 200,905 & 674,617 \\
\hline $\begin{array}{l}\text { - Sub-Ocupación por } \\
\text { jomada** }\end{array}$ & 5,371 & 8,687 & 15,058 & 24,788 & 17,233 & 42,018 \\
\hline $\begin{array}{l}\text { - Sub-Ocupación por } \\
\text { Ingreso }\end{array}$ & 194,948 & 451,979 & 646,927 & 253,589 & 402,015 & 656,504 \\
\hline $\begin{array}{l}\text { Desempleo abiento } \\
\text { Globel } \\
\text { (Total Desocupados) }\end{array}$ & 28,790 & 50,422 & 79,212 & 158,938 & 120,331 & 280,289 \\
\hline $\begin{array}{l}\text { Cesantla Global } \\
\text { (Desocupedos que } \\
\text { tuvieron un empleo) }\end{array}$ & 23,812 & 48,282 & 72,074 & 94,014 & 64,048 & 178,862 \\
\hline $\begin{array}{l}\text { Cosantla Roducida } \\
\text { (Dosocupedos Gua } \\
\text { perdieron el empleo } \\
\text { en eltranscurso del } \\
\text { aho) }\end{array}$ & 23,038 & 48,282 & 71,300 & 41,007 & 48,284 & 81,271 \\
\hline
\end{tabular}

- Incluye ocupados que trahajan voluntarianenta menas de 35 horas a la semana

-. Ocupados que trabajan menos de 35 horas semanales involuntariemente (únicamente Incluye los que sefalaron como rezón para trabajar menos de 35 horas la reducción de la activided economica y el haber encon trando únicamente trabajo parcial).

Elaborado en base a Encuegtas de Hogares de Proposltos Múlliples. MIPLAN 1978 y 1985

cesantla global - el cual mide con bastante aproximación la expulsión de mano de obra resultante de la crisis - que se incrementa en un $148 \%$ durante el mismo periodo. Una primera interpretación de esta similitud de movimientos de los dos indicadores en el tiempo, sería de que el desempleo está mayoritariamente formado por Irabajadores con alguna experiencia, es decir que su expansión ha influido más la expulsión de 
mano de obra, de la esfera de las actividades productivas.

Sin embargo lambién se observa que en el mismo periodo la relación cesantes/desocupados se ha modificado de $91 \%$ en 1978 a $63.8 \%$ en 1985 y el diferencial entre la población desocupada y los trabajadores cesantes (que indicaria el crecimiento de la desocupación originada en los nuevos ingresos de fuerza laboral) ha aumentado en aproximadamente $1320 \%$ durante el periodo.

Estos dalos nos indicarian que el desempleo lendria dos grandes fuentes: una coyuntural, originada en la continua caída de la demanda agregada observada entre 1979 y 1984; y otra en la profundización de la insuficiencia absoluta del proceso de acumulación para absorver la nueva fuerza de trabajo. En nuestra opinión, este último factor se pertila como la principal fuente de desempleo abierto para los próximos anos.

Otro aspecto que merece resaltarse es la pérdida de peso del desempleo estacional como facior explicativo de la desocupación global y de la existencia de trabajadores cesantes (desocupados que estuvierón anteriormente empleados).

En el cuadro 1-A, observamos que la tasa de cesanlía alcanzaba en 1978 un $90 \%$, es decir la desocupación estaba compuesta en su mayor parle por desocupados que hablan estado empleados y habian perdido su empleo hace menos de un año. Ahora bien, en este grupo de desem. pleados generalmente se ubican aquellos trabajadores que desempef.an empleos estacionales y que durante ciertos periodos - generalmenle entre una y otra cosecha agrícola- se encuentran inactivos en espera del llamado de las firmas y/o fincas. En cambio para 1985, este lipo de desocupación representaba menos de un tercio $(32.6 \%)$ del total de los desocupados. Esto nos estaría indicando un cambio cualitativo en el fenómeno de desempleo abierto, éste se habría transformado de fenómeno estacional en lo que podriamos denominar "desempleo de exclusión," es decir, un desempleo que tiene su origen en el ajuste de la demanda de empleo de parte de los empleadores como truto de serios desequilibrios en los mercados de bienes y servicios y de la parálisis del proceso de acumulación. Una cítra que es reveladora de esta situación es la enorme caída de la tasa de cesantia reducida en el espacio rural; aqul los desocupados con menos de un ano de desempleo -dos tercios de los cuales estaban vinculados con aclividades agrícolas en 1985Pasan de representar la casi tolalidad de la desocupación rural (95.7\%), en 1978, a menos de la mitad (41.0\%) en 1985.

Por otra parte, en el espacio urbano la tasa de cesantia reducida cae en aproximadamente $67 \%$ con relación a 1978 , indicando un bloqueo del mercado de trabajo y la disminución de las oportunidades de rotación para la fuerza laboral. 
CUADRO 1-A

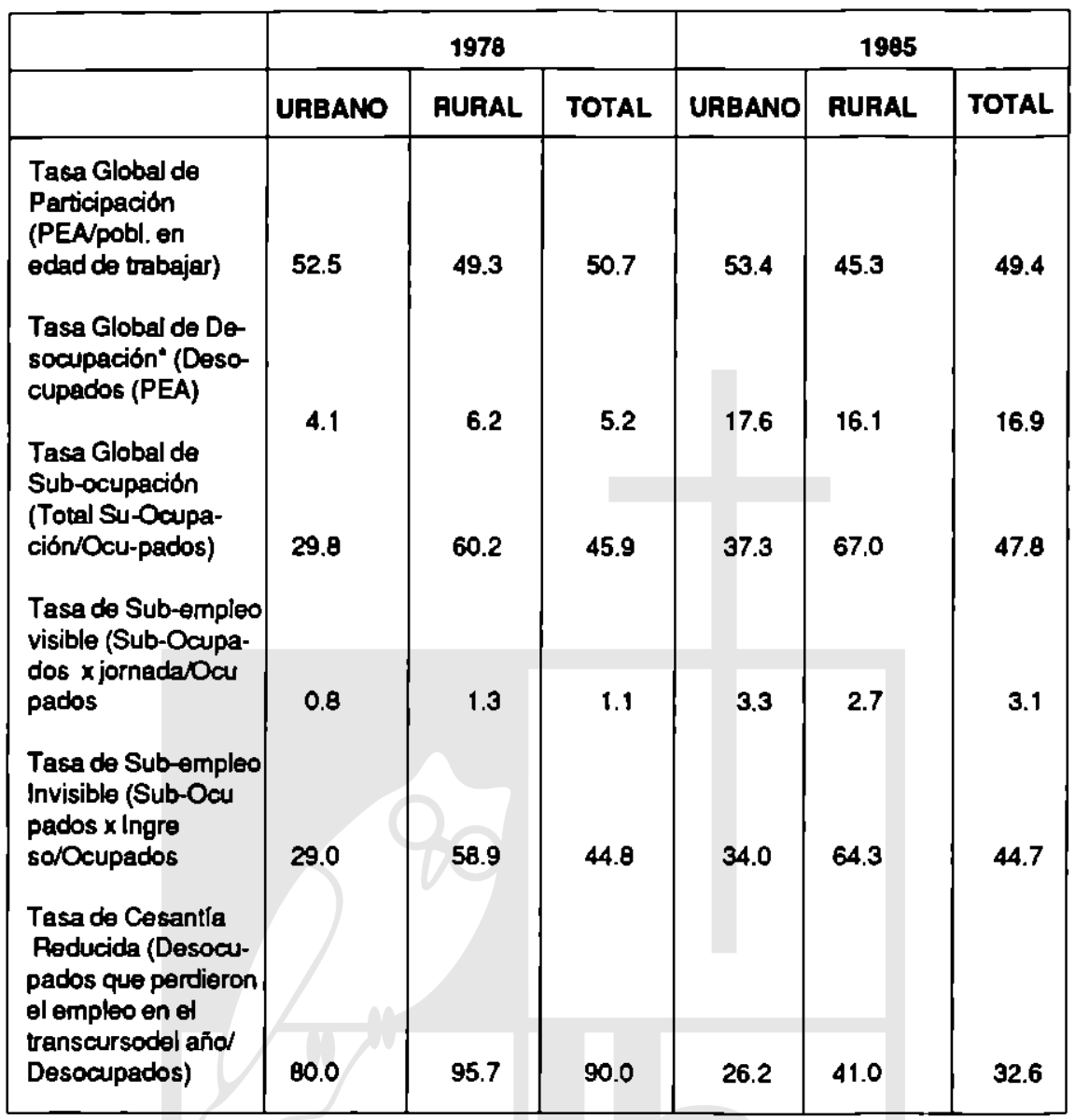

- Incluye a todos los miembros de la PEA que no se encontraban trabajando activamente independientemente de si buscaban activamente empleo al momento de la encuesta.

Elaborado en base a Encuestas de Hogares de Propósitos Múltiples. MIPLAN 1978 y 1985

Otra caracteristica del fenómeno del desempleo es que está ligado fundamentalmente a la fuerte contracción de la actividad agricola; en especial a la disminución de cullivos de exportación como el algodón y los movimienlos de los desplazados, que prácticamente cambian de categoría ocupacional —de trabajador por cuenta propia a desempleado- 
por el simple hecho de la forzada migración campo-ciudad. a que los obliga el conflicto armado. La importancia de esta situación se aprecia claramente en el cuadro 2 (caracteristicas sectoriales de la población ocupada), que muestra como la fuerte calda de la población ocupada en actlvidades agricolas es la que explica fundamentalmente la variación (negativa) en el total de la población ocupada.

En efecto, tal como lo muestra el cuadro anterior la población ocupada en la agricultura disminuye en un $23.8 \%$ enlre 1978 y 1985 al reducirse en 146,261 personas. Excluyendo a la minería, en donde la actividad casi desaparece pero cuyo peso en la estructura ocupacional no es muy importante, solamente se observa una calda de igual imporlancia, a la de

CUADRO № 2

EL SALVADOR: CARACTERISTICAS SECTORIALES DE LA ESTRUCTURA OCUPACIONAL

\begin{tabular}{|c|c|c|c|c|c|c|}
\hline \multirow{2}{*}{$\begin{array}{l}\text { RAMA DE } \\
\text { ACTVIOAD }\end{array}$} & \multicolumn{3}{|c|}{1078} & \multicolumn{3}{|c|}{1985} \\
\hline & UABANO & RURAL & TOTAL & UABANO & RURAL & TOTAL \\
\hline $\begin{array}{l}\text { Agrlature, } \\
\text { Caze y Peaca }\end{array}$ & 82,775 & 532,084 & 614,789 & 64.421 & 404.107 & 468528 \\
\hline Minerla & 1,066 & 4,420 & 5,486 & 622 & 212 & 834 \\
\hline Induatira & 140,017 & 75,006 & 215,023 & 168,166 & 65,696 & 233,862 \\
\hline $\begin{array}{l}\text { Eloctricided, Ges } \\
\text { y Agua }\end{array}$ & 5,259 & 1,245 & 6,504 & 4,635 & 2,666 & 7,301 \\
\hline Constucelon & 41,440 & 34,263 & 75,703 & 34,096 & 18,214 & 53,310 \\
\hline Comerdo & 159,389 & 61,062 & 220,451 & 186,475 & 54,316 & 240,791 \\
\hline Trensporte & 37,874 & 18,728 & 56,602 & 37,046 & 12,344 & 49,390 \\
\hline $\begin{array}{l}\text { Establ. Finande- } \\
\text { rose }\end{array}$ & 11,553 & 446 & 11,999 & 28,759 & 4.434 & 31,193 \\
\hline Servidos & 193,833 & 39,852 & 233,685 & 223,867 & 65,064 & 288,991 \\
\hline TOTAL & 673,158 & 767,080 & $1,440,242$ & 746.087 & 627.053 & $1,373,140$ \\
\hline
\end{tabular}

Elaboredo len bese a Encuestae de Hogeres de Prodaitos Müloples. MIPLAN 1978, 1885. 
las actividades agricolas, en la construcción que disminuye en un $29.5 \%$.

De acuerdo a lo anterior puede considerarse que por la magnitud alcanzada, las caracterisiticas de persistencia que ha asumido y la inexistencia de mecanismo de protección para los desocupados, el desempleo abierto constituye actualmente el principal problema en materia ocupacional.

Sin embargo, la existencia de este importante excedente "coyunlural" de mano de obra no debe de hacernos olvidar que el verdadero problema de las economias sub-desarrolladas esta constituido por la permanente sub-utilización de un importante contingente de la población ocupada (ver cuadro 1).

Hay dos grandes formas de aproximarse a la cuanlificación del subempleo. Primero, se consideran sub-empleados a todos aquellos ocupados que a los niveles de salarios e ingresos vigentes. desearian trabajar voluntariamente más horas. Para nuestro caso se consideran en esta situación los trabajadores que trabajan involuntariamente menos de 35 horas por semana.

En segundo lugar, se consideran sub-empleados a todos aquellos que trabajan jornadas completas ( 40 horas a la semana o más) y perciben una remunteración interior a una norma mínima, por lo general el salario mínimo legal promedio ponderado. Estos trabajadores se consideran "sub-ocupados por ingresos" y constituyen el grueso de la población en situación de pobreza crítica.

Hemos realizado un cálculo (Ver anexo Nó.1) para delerminar la proporción de los ocupados que se encuentran en sub-ocupación por ingresos y es interesante observar que aún antes de la crisis, la tasa de sub-ocupación era igual a la existente en 1985. En 1978, los sub-ocupados por ingreso representan $44.8 \%$ del lotal de la mano de obra ocupada, para 1985 la proporción se manlenía alcanzando 44.7\% (Ver Cuadro N 1-A).

El hecho de que la mayor parte de los sub-empleados estén constituídos por trabajadores visiblemente activos que han encontrado alguna forma alternativa para cubrir el tiempo de trabajo en aclividades ocasionales o de ingresos inestables, sefiala la existencia de un importante "excedente estructural" de mano de obra, en relación a las oportunidades de empleo generadas por el núcleo "moderno-capilalista" de la economla. Esla situación puede observarse más claramente en el Cuadro № 3 que nos muestra las modificaciones de la estructura ocupacional de la población ocupada.

En primer lugar observamos un incremento de los trabajadores por cuenta propia que pasan de representar $27.6 \%$ (1978) a $30.8 \%$ (1985) de los ocupados. 
CUADRO N2 3

EL SALVADOR: CAMBIOS EN LA ESTRUCTURA OCUPACIONAL

DE LA POBLACION OCUPADA

\begin{tabular}{|l|r|r|r|r|r|r|}
\hline \multirow{2}{*}{ CATEGORIA } & \multicolumn{3}{|c|}{1978} & \multicolumn{3}{c|}{1985} \\
\cline { 2 - 7 } & URBANO & RURAL & TOTAL & URBANO & RURAL & TOTAL \\
\hline Patrón & 4,489 & 1,202 & 5,691 & 8,035 & 1,590 & 9,625 \\
Asalariado & 447,178 & 421,237 & 868,415 & 458,843 & 392,752 & 851,595 \\
- Permanente & 284,929 & 194,310 & 479,419 & 323,945 & 133,736 & 457,681 \\
- Termporal & 106,202 & 214,469 & 320,671 & 100,227 & 241,395 & 341,622 \\
Cuenta Propia & 180,505 & 217,737 & 390,242 & 250,872 & 172,341 & 423,213 \\
Fam. No remu- & 40,984 & 126,730 & 167,714 & 28,337 & 60,270 & 88,607 \\
nerado & 673,156 & 767,086 & $1,440,242$ & 746,087 & 627,053 & $1,373,140$ \\
\hline TOTAL & & & & & & \\
\hline
\end{tabular}

Elaborado en base a Encuestas de Hogares de Propositos Múltiples. MIPLAN 1978, 1985.

Por otra parte, lambién se observa un aumento del peso relativo de los asalariados temporales que pasan, entre 1978 y 1985 de $22.3 \%$ a $24.9 \%$ de la población ocupada. Eslos dos cambios pueden estar expresando un aumento de las ocupaciones con ingresos inestables y de la "informalidad" de las actividades. No obstante lo anterior, es de resaltar que el incremento del "cuenta propismo" no constituye el equivalente de una disminución del peso relativo de los asalariados dentro de la población ocupada, pues éstos aumentan también su participación al pasar de $60.3 \%$ en 1978 a $62.0 \%$ en 1985; este incremento es fruto del aumento de los trabajadores ocasionales (temporales), que modifican su participación al inlerior del grupo de los asalariados de $36.9 \%$ a $40.1 \%$ y compensan la disminución de los asalariados permanentes y de las ocupaciones de servicio doméstico.

El hecho de que el aumento del "cuenta propismo" se desarrolle sin una disminución de la participación de los asalariados, estaría sugiriendo que probablemente muchas de eslas "nuevas" aclividades precarias se han desarrollado como respuestas de los nuevos trabajadores a la siluación de desempleo abierto. 
Lo anterior no signilica que el desempleo abierto no haya también sido alimentado por la desaparición de actividades desarrolladas por los cuenta propistas, en particular por las desarrolladas en el espacio rural y vinculadas a las actividades agrícolas.

Este fenómeno se observa claramente en el Cuadro $N^{2} 3$, que sef́ala una importante disminución de los Irabajadores por cuenta propia en el área rural. Entre 1978 y 1985, estos últimos disminuyen en 45,396 personas; es decir en aproximadamente $20 \%$ en relación a 1978 . Esle hecho está vinculado intimamente con la localización del conflicto armado en ciertas áreas rurales, que ha originado importantes flujos de población desplazada. Este último fenómeno también explicaria, en gran medida, significativo aumento de los "cuenta propistas" en el espacio urbano que se incrementan entre 1978 y 1985 en un 39\%; aumenlando de esta lorma su peso relativo dentro de la población ocupada urbana al pasar de representar un $26.8 \%$ en 1978 a $33.6 \%$ en 1985 .

Otra modificación notoria en la estructura ocupacional es la sensible disminución de las ocupaciones estables o permanentes en el área rural. En el período considerado los asalariados rurales permanentes, disminuye en $31.2 \%$ en relación a 1978. En general, los datos del Cuadro № 2 nos muestran una profunda modilicación en la relación empleo ruralempleo urbano que cambia drásticamente entre 1978 y 1985, al pasar de 1.14 ocupados rurales por ocupado urbano en 1978 a 0.84 ocupados rurales por ocupado urbano en 1985 . Este cambio en la dimensión urbanorural del empleo en condiciones de crisis económicamente sefiala una hiperurbanización acelerada en el período y la conversión de una buena parte del sub-empleo rural en sub-empleo urbano. Esta idea nos parece sustentada por los datos de los Cuadros Nos. 1y 3. El enorme aumento de la población de 10 afios y más que experimentan las zonas urbanas a la par de un estancamiento de la población en las zonas rurales, solamente puede ser explicado por una aceleración sin precedenles del flujo migratorio campo-cuidad. Simultáneamente puede observarse un incremento de aproximadamente $30 \%$ en la población urbana sub-empleada, que está en buena medida correlacionado con el impulso que toman las actividades urbanas por cuenta propia que mueslra el Cuadro $N^{2} 3$.

Esla modificación-precarización de la estruclura ocupacional -aumento de los Irabajadores ocasionales y/o por cuenta propia- se va a reflejar en un delerioro de la eslructura de remuneraciones de la población ocupada.

Para hacer una comparación entre 1978 y 1985 se ha reclasificado la esiructura de la distribución de los ingresos percibidos por la población ocupada en 1985, ulilizando colones de 1978. Esla igualación de los poderes adquisitivos de los respectivos ingresos permite desarrollar una estructura comparable (Ver cálculo anexo 2) entre los dos af́os. 
De acuerdo a los datos obtenidos observamos, medidos los ingresos de colones de 1978, un notable deterioro en la estructura de la distribución del ingreso, pues hay un aumenlo significativo de la población ocupada en el tramo de ingresos mensuales de 0 a 99 colones y una notoria disminución de los ocupados que ganaban 200 ó más colones en relación a 1978. Esta situación es truto, en nuestra opinión, de la precarización de la estructura ocupacional.

Sin embargo, la magnilud del deterioro es lal, que no puede excluirse que aún el grupo de los trabajadores permanentes-y generalmente protegidos por un salario legal mínimo - hayan visto disminuir sensiblemente sus remuneraciones, indicando que el peso de la misma ha sido desigualmente distribuido y fundamentalmente recargado sobre la población trabajadora.

Este deterioro de las remuneraciones percibidas por las familias de los trabajadores, actuarla como un factor de retro-alimenlación del problema ocupacional existente, pues frente a la incapacidad de recuperar el poder adquisitivo de sus ingresos frente a las alzas de precios, las tamilias se verían presionadas a presenlar una mayor oferta de trabajo que vendria a agravar el desequilibrio en el mercado de trabajo.

\section{Estructura empresarlal y mercados de trabajo segmentados}

El conjunlo de los problemas sefialados en la sección anterior -desempleo, subempleo y delerioro de las remuneraciones- no se presentan en igual forma si se adopla el criterio de segmentación de los mercados de trabajo.

La hipótesis que mantenemos en esta sección es que la magnitud y la profundidad de dichos problemas varla de acuerdo a la naturaleza de la estructura empresarial en que se inserlan los trabajadores.

De esta forma la naturaleza de las empresas al definir las caracteristicas de los puestos de trabajo que los trabajadores ocupan, estarian de hecho dilerenciando la estructura ocupacional y segmentando los mercados de trabajo.

En este sentido vamos a tralar de evaluar la situación ocupacional en dos segmentos esencialmente distinlos, denominados MERCADOS PRIMARIOS Y MERCADOS SECUNDARIOS. LOS primeros son configurados por las empresas pertenecientes al núcleo oligopólico de la economía y ofrecen puestos de trabajo con salarios relativamente elevados - superiores al mínimo legat, estabilidad de empleo y buenas condiciones de trabajo. En cambio, el segmento secundario es configurado por las pequenas empresas de carácter capilalisla y "cuasi-capitalista" sometidas a un allo grado de competencia en el mercado y presenta en general pues- 
los de trabajo mal remunerados, presenta malas condiciones de trabajo y una marcada inestabilidad en los puestos de trabajo.

A partir de los dalos de la Encuesta de Hogares de 1985, se tratará de evidenciar las características que presenta la estruclura ocupacional segmentada para tralar de sefialar en que segmento del mercado laboral se presentan con mayor gravedad los problemas- de desempleo y subutilización-seflalados anteriormente. Es preciso observar, antes de proceder al análisis de los dalos, dos limilaciones: primeramente, en relación a la segmentación debe aclararse que debido a la escasez de información estadística únicamente se pudo eslratificar la estructura empresarial por el número de personas ocupadas y además la clase mayor solo pudo diferenciarse a partir de las 10 personas ocupadas. En este sentido lo que se considerará "segmento primario" constituye una aproximación bastante tosca de lo que seria el verdadero segmento primario-oligopolístico.

Por otra parte, al considerar las unidades productivas de 1 a 4 personas ocupadas, se están considerando algunas actividades y ocupaciones que no forman parte de un verdadero mercado laboral -caracterizado por la venta y compra de fuerza de trabajo- por su parte su carácter unipersonal y/o de trabajo familiar. ${ }^{3}$

No obstante lo anterior, se considera que la segmemlación utilizada puede proporcionar una buena aproximación de la dilerenciación de la estructura ocupacional.

Primeramenle consideramos la diferenciación en términos de las remuneraciones efecluando una comparación entre los datos de la eslructura ocupacional nacional y la estructura ocupacional urbana, debido a que en esta úllima - por la concentración urbana de la gran actividad industrial y comercial- se manifiesta más claramente la segmentación del mercado laboral.

De acuerdo a los datos globales, la marcada diferencia que se observa entre los segmenlos de 10 y más ocupados (segmento primario) con los establecimientos de 1 a 9 ocupados (segmento secundario) se origina fundamentalmente en la profunda diferencia que muestra la estructura de remuneraciones del sub-conjunto de establecimientos con menos de cuatro ocupados. Por otra parte, a nivel nacional no se observa ninguna diferencia entre lo que se considera segmento primario y el sub-conjunto de establecimienlos de 5 a 9 ocupados que se asume integrando el segmento secundario. Esta ausencia de diferencia se debe, en nuestra opinión, al enorme peso de los empleos agricolas dentro del empleo global y al hecho de que en esle tipo de empleos no existe en la práctica ninguna diferenciación atribuible al mayor o menor tamano de las empresas, pues la casi totalidad de la mano de obra es reclulada en un mercado ge- 


\section{CUADRO Ne 4 \\ OCUPADOS POR NUMERO DE PERSONAS QUE LABORAN \\ EN LA EMPRESA SEGUN TRAMO DE REMUNERACION MENSUAL (porcentejes)}

\begin{tabular}{|c|r|r|r|r|}
\hline \multirow{2}{*}{$\begin{array}{c}\text { Tramo de remuneración } \\
\text { mensual (colones) }\end{array}$} & \multicolumn{4}{|c|}{ personas ocupadas } \\
\cline { 2 - 5 } & $1-4$ & $5-9$ & 1.9 & 10 y más \\
\hline $0-199$ & 47.5 & 27.2 & 45.0 & 27.5 \\
$200-399$ & 25.8 & 30.5 & 26.4 & 28.3 \\
$400-599$ & 12.3 & 20.3 & 13.3 & 20.3 \\
$600-799$ & 7.5 & 11.3 & 8.0 & 13.1 \\
$800-999$ & 2.6 & 5.6 & 2.9 & 5.5 \\
1000 y más & 4.3 & 5.1 & 4.4 & 5.2 \\
\hline TOTAL & 100.0 & 100.0 & .100 .0 & 100.0 \\
\hline
\end{tabular}

FUENTE: Encuesla de Hogares de Propósitos Múltiples.

CUADRO N 5

OCUPADOS URBANOS POR NUNERO DE PERSONAS QUE LABORAN

EN LA EMPRESA SEGUN TRAMO DE REMUNERACION MENSUAL

(porcentajes)

\begin{tabular}{|c|r|r|r|r|}
\hline \multirow{2}{*}{$\begin{array}{l}\text { Tramo de remuneración } \\
\text { mensual (colones) }\end{array}$} & \multicolumn{5}{|c|}{ personas ocupadas } \\
\cline { 2 - 5 } & $1-4$ & $5-9$ & $1-9$ & 10 y más \\
\hline $0-199$ & 36.3 & 15.3 & 39.7 & 9.1 \\
$200-399$ & 27.3 & 26.2 & 27.2 & 21.1 \\
$400-599$ & 15.7 & 27.3 & 17.2 & 28.2 \\
$600-799$ & 10.5 & 15.9 & 11.2 & 21.8 \\
$800-999$ & 3.7 & 7.6 & 4.1 & 9.9 \\
1000 y más & 6.5 & 7.6 & 6.6 & 9.9 \\
\hline TOTAL & 100.0 & 100.0 & 100.0 & 100.0 \\
\hline
\end{tabular}

FUENTE: Elaborado en base a Encuesta de Hogares de Propósitos Múltiples. MIPLAN. 1985 
neral en el que no existen diferencias entre el salario medio y el salario mínimo legal. ${ }^{4}$

En el espacio urbano si se verifica la tendencia a la segmentación del mercado laboral ya que además de la diferenciación global existente entre los segmentos de 1 a 9 ocupados y de 10 ocupados y más se manifiesta una diferenciación entre las eslructuras de remuneraciones del sub-segmento de 5 a 9 ocupados con el denominado "segmento primario." Esta dilerencia se origina por el mayor peso-en términos de generación de empleos- de las grandes empresas y de la administración pública en el segmento de establecimientos con más de 10 ocupados. En relación a los datos disponibles observamos que la mayor parle de los ocupados del segmento laboral dominado por las empresas modernas tendia a situarse arriba del salario mínimo legal (aproximadamenle $₫ 375.00$ para el tolal de los mercados urbanos), ya que alrededor del $70 \%$ de los ocupados del segmento obtenian una remuneración mayor. En cambio en el segmento de las pequefias y de las microempresas, la estructura de remuneraciones presentaba una distribución totalmente diferente, al concentrarse la mayoria de los ocupados $(60.9 \%)$ abajo de los 400 colones mensuales. La diferencia entre los segmentos de 5 a 9 ocupados y de 10 y más ocupados es marcada. En el primero se observa que el $41.5 \%$ de los ocupados percibe ingresos inferiores a los $\varnothing 400.00$ por mes, en cambio en el otro segmento únicamenle encontramos al $30.2 \%$ de la población. Por otra parte, lambién se observa que la mayor parte de los ocupados del segmento de las pequefias empresas tendía a concentrarse en una escala de ingresos que iba de los $₫ 200.00$ a los $₫ 599.00$ por mes, en cambio para el segmento de 10 y más ocupados la concentración se verificaba dentro de unos limites que iban de los $₫ 400.00$ a los $₫ 799.00$ mensuales.

En sintesis, de acuerdo a to analizado puede decirse que la hipótesis de la diferenciación salarial en función del tamaño de las empresas solo se verifica parcialmente para el espacio laboral urbano. Este hecho no invalida la idea de la segmenlación, sino que más bien refuerza la idea de que el faclor delerminante no es el tamaño de la empresa sino su poder de mercado.

En relación a los olros problemas que ocupan nuestra atención, el cuadro $N^{2} 6$ nos permite apreciar las caracteristicas diferenciadas del problema del desempleo abierto.

La evidencia empírica muestra, que cuando se considera exclusivamente a los desempleados cesantes -que tuvieron anteriormente empleo- observamos que la mayor parte de la población desempleada $73.9 \%$ provenia de pequehos establecimientos (hasla 9 ocupados). Esta proporción se eleva en el mercado laboral urbano, en donde el $76.1 \%$ de 
CUADRO N2 6

DESOCUPADOS SEGUN LA ESTRUCTURA OCUPACIONAL

DE PROCEDENCIA

\begin{tabular}{|c|r|r|l|}
\hline Tramo Ocupaclonal & Total & Urbano & Rural \\
\hline $1-4$ & 101,407 & 65,124 & 36,283 \\
$5-9$ & 91,878 & 47,205 & 44,673 \\
10 y más & 68,141 & 35,246 & 32,895 \\
\hline TOTAL & 261,426 & 147,575 & 113,851 \\
\hline
\end{tabular}

FUENTE: Encueste de Hogares de Propósilos Múhliples. MIPLAN, 1985.

los desempleados cesantes habia trabajado en el segmento que anteriormente se ha definido como "secundario" (pequenas empresas tradicionales). Esta situación estarla conlirmando la alta inestabilidad de los puestos de trabajo de este segmento laboral y a la vez mostrando que las actividades desarrolladas a su interior presentaban limitaciones para cumplir funciones anticíclicas, ya que en conjunto muestran bastanle sensibilidad a las fases de contracción de la actividad económica general. El origen de esta sensibilidad radica en el hecho de que el empleo de este segmento no proviene en su totalidad de actividades autónomas. Por el comrario una buena canlidad de las ocupaciones de este segmento se originan en actividades mercantiles que se encuenlran inlimamente vinculadas a la dinámica del núcleo moderno de la economía.

Lo anterior quedaría ampliamente confirmado con los datos del cuadro siguiente.

El Cuadro N 7 nos confirma que aún en el segmento de las microempresas - en donde existe una marcada presencia del cuenta propismola mayor proporción de desempleados (63.2\%) se originó en la categoría de los asalariados. Por otra parte, los datos indican que aún excluyendo los empleados domésticos, el segmento que mostraba una mayor contracción ocupacional (57.4\% de los desocupados cesantes) era el de los pequenos eslablecimientos. Esle movimiento contradeciría la idea de un sector totalmente autónomo, que algunos investigadores han formulado sobre el sector de las microempresas, pues en el corto plazo también este sector sufriría las consecuencias de una drástica reducción de la demanda agregada.

El hecho de que las mayores tasas de desocupación se presenten en el segmento de las actividades unipersonales y de las microempresas, evidencia que éslas actividades ajustan el mercado de trabajo en con- 
CUADRO N ${ }^{2} 7$

DESOCUPADOS CESANTES SEGUN CATEGORIA OCUPACIONAL

Y ESTRUCTURA OCUPACIONAL DE PROCEDENCIA*

\begin{tabular}{|c|c|c|c|c|c|c|}
\hline \multirow[b]{2}{*}{$\begin{array}{l}\text { Tramo } \\
\text { Ocupaclo- } \\
\text { nal }\end{array}$} & \multicolumn{6}{|c|}{ Categorla Ocupaclonal } \\
\hline & Total & Patrón & $\begin{array}{l}\text { Cuenta } \\
\text { propla }\end{array}$ & $\begin{array}{l}\text { Asalarla- } \\
\text { do perma } \\
\text { nente }\end{array}$ & $\begin{array}{l}\text { Asalarla- } \\
\text { do perma } \\
\text { nente }\end{array}$ & $\begin{array}{l}\text { Fam. no } \\
\text { remunera } \\
\text { da }\end{array}$ \\
\hline $\begin{array}{r}1-4 \\
5-9 \\
10 \text { y más }\end{array}$ & $\begin{array}{l}72,930 \\
18,717 \\
67,995\end{array}$ & $\begin{array}{l}186 \\
214 \\
959\end{array}$ & $\begin{array}{r}21.184 \\
127 \\
765\end{array}$ & $\begin{array}{r}17,557 \\
7,295 \\
20,147\end{array}$ & $\begin{array}{l}20,519 \\
10,954 \\
45,794\end{array}$ & $\begin{array}{r}5,484 \\
127 \\
330\end{array}$ \\
\hline TOTAL & 159,642 & 1,359 & 22,076 & 44,999 & 05,267 & 5,941 \\
\hline
\end{tabular}

FUENTE: Elaborado en base a Encueslas de Hogares de Propósitos Múltiples. MIPLAN 1985.

*: Excluye servicio doméstico.

diciones normales absorbiendo el "excederte estructural" de mano de obra, pero tiene una muy limitada capacidad de ajuste anti-cíclico pues no sólo no pueden absorber el total del excedente "coyuntural" que origina la contracción de la actividad económica sino que también tienden a "vaciarse" siguiendo las fases de la actividad económica; sin embargo, el aumento observado en los trabajadores por cuenta propia indicarla la existencia de un proceso permanente de Desirucción/re-creación" en las actividades unipersonales.

En relación a la sub-utilización de la mano de obra, la evidencia empírica nos indica que el problema del sub-empleo tiende a presentarse predominantemente en lo que se ha denominado segmento "secundario."

Tal como lo muestra el siguiente Cuadro $N^{*} \mathbf{8}$, el fenómeno de la subocupación visible tiende a concentrarse en las actividades de tipo unipersonal 0 en los establecimientos de hasta cuatro personas ocupadas.

Los datos nos sefialan que - sin considerar los motivos de aceptación del tiempo parciał la mayor proporción (66.8\%) de la mano de obra que trabaja menos de la jornada normal se concentra en el grupo de establecimientos de 1 a 4 ocupados. Esta proporción se manliene también en el espacio urbano, ya que el segmento de los micro-establecimientos absorbe el $66.4 \%$ de la población que trabaja menos de las 35 horas semanales. 
TRABAJADAS Y DE ESTABLECIMIENTO (MIles)

\begin{tabular}{|c|c|c|c|c|c|c|c|c|}
\hline \multirow{2}{*}{$\begin{array}{l}\text { Horas sema- } \\
\text { nales traba- } \\
\text { Jadas }\end{array}$} & \multicolumn{4}{|c|}{ Pais tolal } & \multicolumn{4}{|c|}{ Pala Urbano } \\
\hline & $1-4$ & $5-9$ & $\begin{array}{l}10 y \\
\text { má }\end{array}$ & Tolal & 1.4 & $5-9$ & $\begin{array}{l}10 y \\
\text { más }\end{array}$ & Totel \\
\hline No trabajó & 8.7 & 1.2 & 6.5 & 16.4 & 6.8 & 1.0 & 4.8 & 12.6 \\
\hline 1-16 & 18.2 & 0.7 & 3.6 & 22.6 & 11.2 & 0.6 & 1.5 & 13.3 \\
\hline $17-34$ & $62-1$ & 5.7 & 26.4 & 94.2 & 36.2 & 3.5 & 16.0 & 55.7 \\
\hline $35-45$ & 209.9 & 41.4 & 225.2 & 476.4 & 117.0 & 27.5 & 125.0 & 269.5 \\
\hline 46 y más & 466.9 & 57.2 & 239.4 & 763.5 & 273.1 & 31.4 & 90.4 & 394.9 \\
\hline TOTAL & 765.8 & 106.2 & 501.1 & $1,373.1$ & 444.3 & 64.0 & $237.8^{*}$ & 746.1 \\
\hline
\end{tabular}

FUENTE: Elaborado en base a Encuesta de Hogares de Propósitos Múltiples. MIPLAN, 1985.

$\because$ : Ajuste de residuos

Se considera las 35 horas semanales trabajadas como el IImite inferior de una semane laboral normal.

También se observa que es en el segmenlo "secundario" en donde se produce el mayor despliegue de fuerza de Irabajo -en términos de horas trabajadas- asi del total de la mano de obra ocupada en ese segmento de mercado ( 1 a 9 ocupados) el $60 \%$ trabaja más de 46 horas semanales (47.8\% para el segmenlo de más de 10 ocupados). En el espacio urbano la dilerencia entre los dos segmentos se presenta en forma más marcada, pues, al inlerior del segmento de 10 y más solamente un $38 \%$ de la mano de obra sobrepasaba las 46 horas semanales de trabajo, en el segmento de 9 y menos ocupados se mantenía la proporción de $60 \%$ encontrada a nivel nacional.

El hecho de que tanto la sub-utilización como la sobreulilización liendan a concentrarse en el segmento de los pequenos establecimientos nos confirmaría la idea de la segmenlación global del mercado de trabajo, ya que las ocupaciones de mala "calidad" —precarias, muy intensivas en términos de jornadas de trabajo, o bien inestables con semanas normales y anormales en función de la demanda de bienes y servicios entrenlada-se distribuyen en forma disimétrica en la estructura ocupacional.

La sub-ocupación por ingreso, también tiende a concentrarse dentro del segmento de 9 y menos ocupados, como lo muestran los cuadros Nos. 4 y 5. Si lomamos como norma de ingresos la cantidad de $₫ 299.5$ mensuales (1985) para el país total y el salario minimo mensual urbano ( $₫$ 375.00 aproximadamente) para los mercados de trabajo urbano y suponemos una distribución normal de las remuneraciones en cada tramo de 
ingreso; se observa a nivel nacional aproximadamente el $60 \%$ de los ocupados del segmenlo laboral de los pequeños eslablecimientos pueden considerarse como afectados por la sub-ocupación invisible. Esla sub-ocupación disminuye en el tramo de 10 y más ocupados hasla 41. 7\%. También se observa una caída de la sub-ocupación en el Iramo de los establecimientos de 5 a 9 ocupados. Como se explicó anteriormente, la similitud de las tasas de sub-empleo invisible existente entre el sub-segmento de 5 a 9 con el segmenlo de 10 y más ocupados, sería fruto de la ausencia de diferenciación de la estruclura salarial de las ocupaciones agrícolas.

En cambio en los mercados urbanos las diterencias son marcadas, utilizando el salario mínimo tendriamos que el $57.6 \%$ de los ocupados del segmento de 9 y menos se encontraba en situación de sub-ocupación. Esta sub-ocupación sería más grave en el tramo de las microempresas (hasta 4 ocupados) en donde se observaría un $60.3 \%$ de sub-ocupación por ingresos y disminuiria en el Iramo de 5 a 9 ocupados hasta un $38.3 \%$. Para el segmento "primario" (10 y más ocupados) la sub-ocupación afectaría únicamente el $27.6 \%$ de la mano de obra visiblemente ocupada. Debe sefialarse en este último caso, que esta tasa es muy elevada considerando que este es un segmento "prolegido", por una legislación que ordena que la diferenciación de la estructura salarial debe hacerse a partir de una tasa de salarios que corresponde al salario mínimo legal. También debe sefialarse que como el segmento de 10 y más ocupados, es solamente una aproximación al verdadero segmento "primario" (núcleo moderno-oligopolístico de la economía) puede esperarse que la diferencia real entre las tasas de sub-ocupación de ambos segmentos sea más marcada. Esto es sugerido por la misma estruclura de la distribución de remuneraciones urbanas que muestra que la mayor parte $(42 \%)$ de la población ocupada del segmenlo de 10 y más recibia remuneraciones que iban desde 1.2 salarios minimos hasta 2.1 salarios minimos, al ubicarse en los tramos centrales de la distribución.

En síntesis, de acuerdo a los dalos analizados, puede decirse que existe una cierta evidencia de segmentación de los mercados laborales, en particular del mercado de trabajo urbano. La conclusión más importante que se deriva de este hecho es que la solución a los problemas ocupacionales - desempleo y subempleo- no puede limitarse a la creación de "cualquier puesto de trabajo" a través del estímulo a la creación o mantenimiento de micro-establecimientos o a la "informalización" de la estructura ocupacional, sino que por el conlrario, la solución demanda de la transiormación de las condiciones laborales del segmento secundario, la transformación de algunas estructuras empresariales y el impulso al crecimiento de las actividades modernas vinculados al segmento primario. ${ }^{5}$ 
Excedente de mano de obra y segmentaclón de la estructura ocupaclonal

En la primera parte de este trabajo se ha sefialado que una de las fuentes de la segmenlación y de la helerogeneidad de la estructura ocupacional sería la existencia de un considerable "excedente estructural" de mano de obra en los mercados de trabajo.

El "excedemle esiructural" de mano de obra está configurado por aquella parte de la población económicamenle activa que constituye una sobre oferla en relación a la demanda de trabajo asalariado del núcleo moderno-capitalista de la economia. Estas personas no se convierten en desocupados porque a través de un despliegue activo de estrateglas de sobrevivencia logran insertarse en la estructura económica en actividades generalmente mercantiles y primitivas.

En esle sentido puede postularse que la existencia del "excedeme de mano de obra contribuye a la subsistencia a lo largo del tiempo de formas pre-capitalistas y capitalistas primitivas de organización de la producción."'s

Este tipo de actividades han sido convencionalmente denominadas "actividades informales" y dada su helerogeneidad7 generalmente se les agnupa en el llamado "sector informal" por oposición al núcleo o sector capilalista de la economia.

Es necesario sehalar, que la permanencia y desarrollo de estas actividades puede lambién ser influido por la depresión de los salarios reales. Este hecho que se manifiesta en el delerioro de los ingresos de la unidad lamiliar, obliga a los individuos en edad de Irabajar a lanzarse al mercado laboral en busca de trabajo. Sin embargo, dada la insuficiente demanda de empleo del sector moderno, esta fuerza de trabajo pasa también a formar parte de la fuerza laboral excedemlaria.

En este sentido puede decirse que la masa de Irabajadores que se insertan en el sector informal urbano tendrla un doble origen: por un lado, un excedente de luerza de trabajo primaria -jefes de familia- que se ve constrefiida a autocrearse alguna actividad para garantizarse alguna participación en la distribución del producto social; y por otra parte, está alimentada por un importante flujo de fuerza de trabajo secundarla- no jefes de familia - que buscan desarrollar alguna aclividad con el objetivo fundamental de oblener ingresos adicionales, que compensen la precariedad del ingreso del jefe de farmilia. ${ }^{.}$

Esto implica que la magnitud del sector inlormal urbano está asociada a la magnilud del excedente de mano de obra y a la posibilidad de los Irabajadores excedentarios de generar algún ingreso aceptable en las actividades alternalivas. De esta forma puede decirse que el sector infor- 
mal actúa como regulador del mercado de trabajo - fundamentalmente urbano- al amortiguar las presiones de demanda de puestos de trabajo. ${ }^{9}$

Ahora bien, el resultado de esta regulación -efectuada por la autocreación de ocupaciones- es una esinuctura ocupacional altamente diferenciada en relación a la "calidad" de los puestos de trabajo.

Primeramente las ocupaciones del "segmento" o "sector" informal se diferencian, en relación a las del sector moderno, en la capacidad de promoción de niveles aceptables de bienestar para la población trabajadora involucrada en dichas actividades y en las características de la estructura productiva que potencian y reproducen.

En relación al primer punto, la evidencia empirica (Cuadro $N^{4}$ 9) senala que este tipo de ocupaciones no permite, en general, alcanzar ingresos que promueven un nivel minimo de bienestar material.

De acuerdo a la información, en 1986 la mayor parte de los 1rabajadores por cuenla propia percibian menos de $₫ 400.00$ mensuales. El $44.5 \%$ de los trabajadores masculinos y el $72.0 \%$ de los trabajadores femeninos se enconlraban bajo esta línea de ingresos. Por otra parte, las cifras nos señalan también la exislencia de un diferencial negalivo, en relación a las remuneraciones obtenidas por el uso de la fuerza de trabajo, entre el sector informal y el sector modemo. En efeclo, si consideramos al grupo de asalariados permanentes representativo de los ocupados en el sector moderno, observamos que a diferencia de los trabajos por cuenta propia, las remuneraciones de esle grupo tienden a concentrarse en un rango de $\$ 400.00$ a $\$ 800.00$ mensuales. En cambio para los trabajadores cuenta propistas de ambos sexos, las remuneraciones tienden a concentrarse en un intérvalo que va de $₫ 100.00$ a $₫ 400.00$ por mes.

Es evidente que un mayor nivel de ingresos está asociado a un mayor nivel de bienestar, en la medida que permile la adquisición de una mayor canlidad de bienes de consumo. En este sentido, puede decirse que los hogares con jefes de familia vinculados al sector informal tienen menores posibilidades de cubrir niveles de consumo que permitan alcanzar un nivel mínimo de bienestar. A este respecto, es interesante sefialar que si se adopta el costo monetario mensual del consumo familiar normativo de alimentos (aproximadamente 600.00 en 1985), únicamente el $24 \%$ de los trabajadores por cuenta propia podían satisfacer las necesidades de su grupo familiar sin necesidad de los ingresos complementarios de otros miembros. Otro indicador de la poca capacidad de eslas ocupaciones para promover niveles mínimos de bienestar personal viene dado por la intensidad de la jornada de trabajo en relación al bajo nivel de remuneraciones percibidas. 


\section{CUADRO NN 9 \\ ESTRUCTURA OCUPACIONAL SEGUN TRAMOS \\ DE REMUNERACION MENSUAL AMSS 1986}

\begin{tabular}{|c|c|c|c|c|c|c|c|c|c|c|}
\hline Colonee & Patrono & $\mathbf{x}$ & $\begin{array}{l}\text { Asala- } \\
\text { rlado } \\
\text { Perma- } \\
\text { nonito }\end{array}$ & • & $\begin{array}{l}\text { Asala- } \\
\text { rlado } \\
\text { Tompo } \\
\text { ral }\end{array}$ & 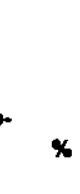 & $\begin{array}{l}\text { Traba- } \\
\text { ladores } \\
\text { por } \\
\text { Cuenta } \\
\text { propla }\end{array}$ & 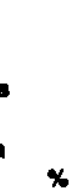 & $\begin{array}{l}\text { Asala- } \\
\text { rladoe } \\
\text { Porma- } \\
\text { nentes }\end{array}$ & $\%$ \\
\hline $0000-0075$ & - & - & 228 & 2.3 & 228 & 4.9 & 1,596 & 3.4 & 684 & 0.4 \\
\hline 0076.0225 & 228 & 1.9 & 2,166 & 21.3 & 596 & 34.1 & 10,032 & 21.3 & 4,332 & 2.3 \\
\hline $0226 \cdot 0450$ & 1,140 & 9.4 & 3,420 & 33.7 & 1,024 & 39.0 & 16,188 & 34.4 & 36,368 & 19.2 \\
\hline $0451-0899$ & 3,648 & 30.2 & 3,762 & 37.1 & 798 & 17.1 & 11,172 & 23.7 & 94,050 & 49.5 \\
\hline $0900-1999$ & 4,560 & 37.7 & 456 & 4.5 & 228 & 4.9 & 5,244 & 11.1 & 45,828 & 24.1 \\
\hline 2000 y más & 2,500 & 20.8 & 114 & 1.1 & - & - & 2.850 & 6.1 & 8,550 & 4.5 \\
\hline TOTAL & 10,084 & 100.0 & 10,146 & 100.0 & 4,674 & 100.0 & 47,082 & 100.0 & 189,810 & 100.0 \\
\hline
\end{tabular}

- Ocupados en Microempresas no-unipersonales sector inlormal

- Asalariados sector moderno

\section{CUADRON 10}

TRABAJADORES URBANOS NO ASALARIADOS SEGUN SEXO Y HORAS SEMANALES TRABAJADAS. 1985

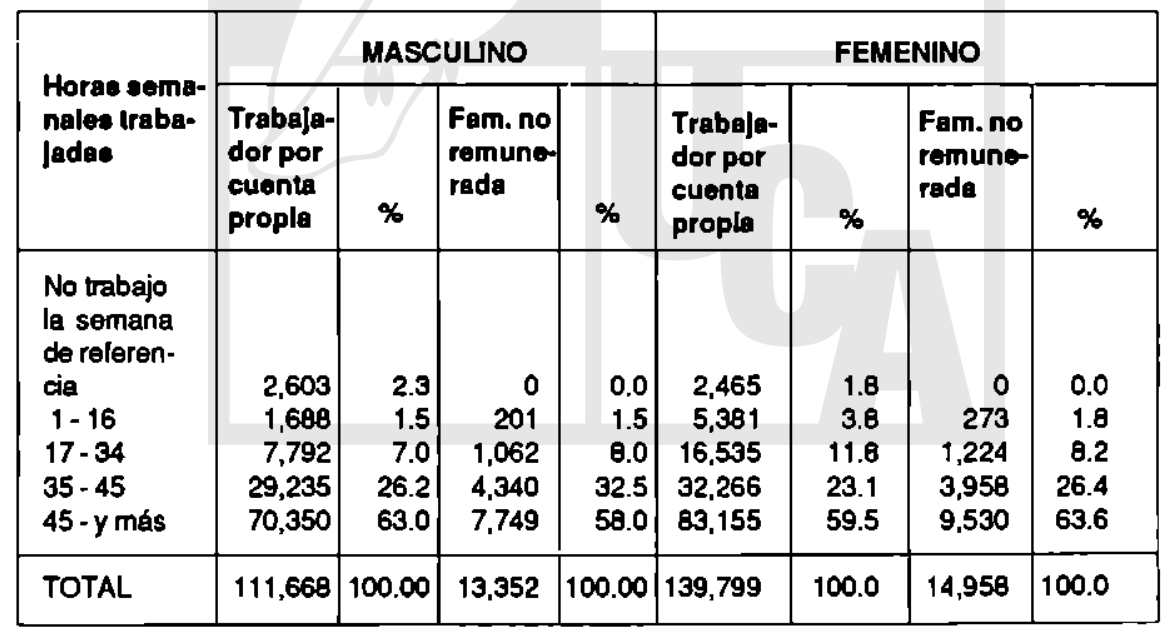

FUENTE: Elaborado en base a las encuentes de Hogares de Propósitos Múltiples. MIPLAN, 1985. 
Si consideramos como semana laboral normal un tiempo de trabajo equivalente a 44 horas semanales -en base a 8 horas de trabajo diario--, observamos que la mayoría de los trabajadores del sector informal trabajarian más de seis días por semana o bien más de ocho horas diarias.

No obstante, este mayor uso de la fuerza de trabajo, no está ligado a un mayor flujo de ingresos, pues como se puede observar en los dalos de los cuadros anteriores, a pesar de que aproximadamente el $60 \%$ de los trabajadores, cuentapropistas trabajan más de 45 horas semanales," únicamente ùn $40 \%$ alcanzaba un ingreso igual o superior a los $\$ 100.00$ semanales.

En relación a la estruclura productiva, se ha sefialado anteriormente. que estas actividades de tipo "informal" tienen su origen, fundamentalmente, en el "excedente estructural de mano de obra." En este sentido, la estructura productiva que es fruto de esla aulogeneración de ocupaciones está conformada por establecimientos de tipo personal con muy bajo requerimiento de capital o bien por eslablecimientos caracterizados por un uso mínimo de fuerza de trabajo asalariada. Estas características -que son consustanciales al proceso de "gestación espontánea" de las actividades - tienden al limitar el desarollo de eslos establecimienlos hacia niveles aceptables de eficiencia y productividad. Por otra parte, los espacios de mercado en que se desenvuelven estos establecimientos son constantemenle "remodelados" por la competencia de los establecimienlos del sector moderno-capitalista, limitándose de esta forma las posibilidades de expansión- en ventas y en ingresos- para el sector informal.

De esta situación, se deriva que la estructura productiva resultante del desarrollo de las actividades informales tiene una limitada dinámica de crecimiento en términos ocupacionales y en términos de contribución a la producción nacional de bienes y servicios.

En relación a su capacidad de creación de empleos - que constituye un buen indicador de la capacidad de expansión de los establecimientos creados-observamos, en el Cuadro № 11 , que ésta es casi inexistente.

Partiendo del hecho de que los propietarios que declararon no tener empleados indican simultáneamente que el carácter unipersonal o familiar de su establecimiento no ha cambiado desde que fue conslituido, observamos que prácticamente la mayoría de los establecimientos de la muestra $(83 \%)$ no han sido capaces de generar nuevas ocupaciones. La rama de actividad en donde mayor "estabilidad" se observa es la rama de iransporte (100\%), probablemente por la existencia de una adecuación relativamente fija entre el instrumento de trabajo (medio de transporte) y los Irabajadores vinculados a las actividades de conducción y co- 


\begin{tabular}{|c|c|c|c|c|c|c|c|c|}
\hline Pama & & & \multicolumn{2}{|c|}{$\begin{array}{l}\text { Tlempo } \\
\text { Establect } \\
\text { do }\end{array}$} & Aumento & \multirow[t]{2}{*}{ Dlsminuyo } & \multirow[t]{2}{*}{$\begin{array}{l}\text { Sin cam- } \\
\text { blo }\end{array}$} & \multirow[t]{2}{*}{$\begin{array}{l}\text { No tlone } \\
\text { empleadoe }\end{array}$} \\
\hline & & Tolal & $\begin{array}{l}\text { Me- } \\
\text { nos } \\
\text { de } 1 \\
\text { afo }\end{array}$ & \begin{tabular}{|l|} 
Un \\
ấo \\
y \\
más
\end{tabular} & & & & \\
\hline $\begin{array}{r}\text { Industria } \\
\text { Comercio } \\
\text { Transporte } \\
\text { Est. Financ. } \\
\text { Servicios }\end{array}$ & $\begin{array}{r}53 \\
12 \\
6 \\
6 \\
25\end{array}$ & $\begin{array}{l}(100 \%) \\
(100 \%) \\
(100 \%) \\
(100 \%) \\
(100 \%)\end{array}$ & $\begin{array}{r}7 \\
25 \\
2 \\
- \\
3\end{array}$ & $\begin{array}{r}46 \\
96 \\
6 \\
6 \\
22\end{array}$ & $\begin{array}{rr}9 & (17.0 \%) \\
10 & (8.3 \%) \\
- & - \\
1 & (16.7 \%) \\
5 & (20.0 \%)\end{array}$ & $\begin{array}{rr}3 & (5.7 \%) \\
7 & (5.8 \%) \\
- & - \\
- & - \\
1 & (4.0 \%)\end{array}$ & $\begin{array}{r}22(41.5 \%) \\
37(30.6 \%) \\
8(100 \%) \\
5(83.3 \%) \\
16(64.0 \%)\end{array}$ & $\begin{array}{c}19(35.8 \%) \\
67(55.3 \%) \\
- \\
- \\
3(12.0 \%)\end{array}$ \\
\hline TOTAL & 213 & & 37 & 176 & 25 & 11 & 88 & 89 \\
\hline
\end{tabular}

FUENTE: Encuesta de Hogares de Propósitos Múltiples (AMSS). MIPLAN, 1986

bro. La otra rama que presenta menos variaciones ocupacionales. es la rama de comercio $(85.9 \%)$, esta rama presenta también el mayor porcenlaje de establecimientos sin empleados (55.3\%), lo cual podría indicar ol carácter unipersonal y de lípica subsistencia de las actividades comerciales informales. Lo anterior no signilica que algunos establecimientos y/o actividades no tengan alguna capacidad de expansión, pues tal como se observa en el cuadro, entre los establecimientos que experimentaron variación en la ocupación predominaron (11.7\%) los que aumentaron sobre los que disminuyeron (5.2\%). Sin embargo, creemos que los dalos sefialan que este tipo de actividades muestran una capacidad de absorción ocupacional relativa, pues no presentan grandes obstáculos para la autogeneración de la "unidad informal"; pero tienen una muy limitada capacidad de generación de ocupación.

Estas actividades "informales" presentan lambién una limilada contribución a la generación de bienes y servicios debido a los bajos niveles de capital con que operan y que las limitan a utilizar tecnologías simples y muchas veces arcaicas.

La distribución de establecimientos inlormales por relación capital tijo utilizado por personal ocupado (Cuadro № 12) nos muestra el predominio de unidades con exiguos niveles de activos fijos.

La mayoria de los establecimientos (69\%) lienen una dotación (valor) 


\section{CUADRO NP 12}

MCROEMPRESAS NO AGRICOLAS POR RELACION CAPITALTTAABAJO* SEGUN RAMA DE ACTIVIDAD ECONOMICA. MUESTRA AMSS. 1986

(Colones)

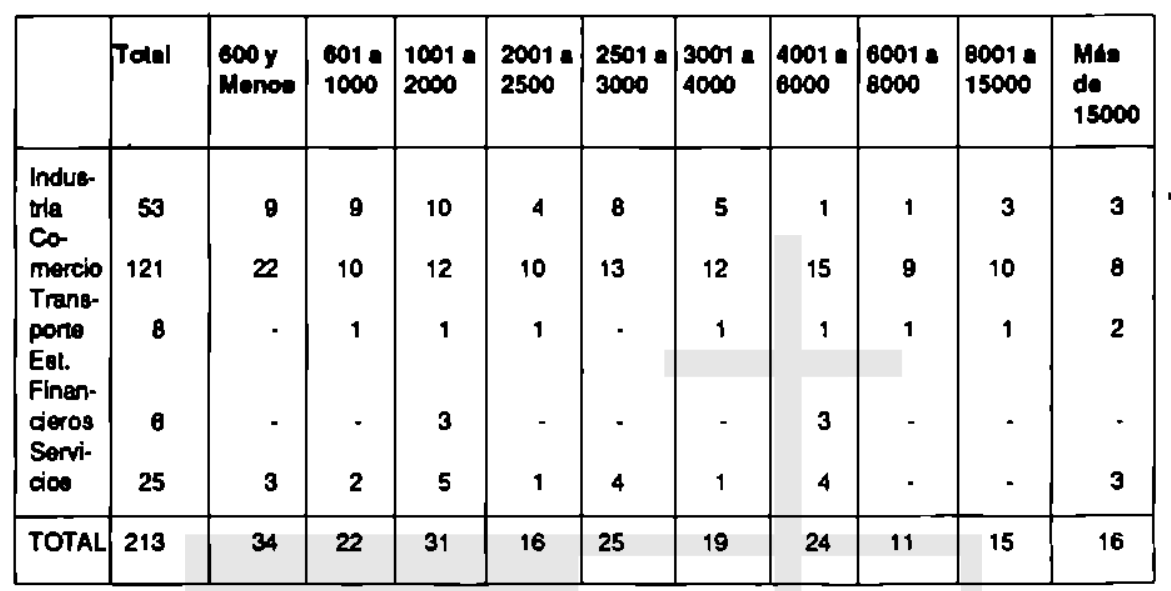

: Capital fjo/trtal Personal Microempresa.

FUENTE: Enavesta de Hogares de Propdsitos Múliples (AMSS). MIPLAN, 1986.

de capital por hombre ocupado menor de $44,000.00$ y aproximadamenle la mitad apenas alcanza a llegar a una dolación de $₫ 2,500.00$ por trabajador. Por otra parte merece resaltarse que las más bajas dotaciones de capital se presentan en las actividades de producción, ya que para el total de microempresas industriales únicamente un $15 \%$ sobrepasaba el Ilmite de los $₫ 4,000.00$ por trabajador y más de la mitad (60.3\%) se encontraba entre 600 y 2,500 colones. Eslo conslituiria una clara evidencia del bajo grado de mecanización de estas actividades y en consecuencia de su débil o nula capacidad de expansión. Para evidenciar más esta baja relacion capital-trabajo utilizaremos el valor promedio actualizado (colones 1986) de la dotación capilal/rabajo de los establecimientos manutacturados de más de 20 empleados (núcleo-capilalista).

En 1978, de acuerdo al censo de manufacturas diversas, los establecimientos de más de 20 empleados tenlan una dotación de aproximadamente $₫ 20,600.00$ por trabajador. Esto equivaldria en colones de 1986 a más o menos $₫ 54,900.00 .^{10}$ Por consiguiente, la generación "espontánea" de actividades informales lendería a reproducir una estructura productlva altamente heterogénea en términos de dotación de capital y esta siluación darla lugar, en general, a un "clrculo perverso": bajas dotaciones de capital/trabajo llevarian a bajas productividades por puesto y por establecimiento; y la baja productividad determinaria bajos niveles 
de producción y de ingresos.

Esta siluación puede verificarse también con los dalos del Cuadro № 9 que nos muestra como los ingresos de los asalariados de las micro-empresas tienden a concentrarse en niveles inferiores a los $₫ 450.00$ mensuales a diferencia de los ingresos asalariados permanentes que tienden a concentrarse arriba de ese nivel.

Ciertamente, en esta distribución podría influir el mayor grado de educación de algunos asalariados del seclor moderno, en particular para aquellos que superaban el nivel de los $₫ 900.00$ mensuales, sin embargo nosotros consideramos que en general los elementos más importantes de esla diferenciación provienen de la mayor produclividad de los establecimientos modernos y del mayor conlrol de mercado (y de los precios) que caracteriza a las empresas de este sector. ${ }^{11}$

En resumen, la información analizada a lo largo de esla sección nos sefiala que, dadas las limitaciones - en el acceso al capital- que acompahan al proceso de auto-creación de ocupaciones y a los limitados espacios de mercado que le olorga el núcleo modemo-capitalista, la estructura productiva y ocupacional resultanle tiende fundamentalmente a reforzar la desigual distribución del ingreso y la segmentación de la estructura laboral.

\section{Rellexlones finales}

Una primera conclusión de importancia que podemos derivar del análisis de la segmentación es que la condicción de pobreza está intimamente relacionada con la pertenencia a un delerminado segmento de la estructura ocupacional. En efecto el sub-empleo por ingresos que es una caracterislica asociada a la condición de pobreza se concentra fundamentalmente en el grupo de trabajadores vinculados a los llamados segmentos secundario y el sector informal.

Lo anterior implica que las políticas de empleo y las políticas de reducción de la pobreza son necesariamente complementarias entre si, y deben de ser concebidas en función de la recomposición de la estructura productiva.

Otra importante conclusión que se insinúa a partir de los resultados de este trabajo es que las diferencias salariales de los Irabajadores resultan lundamentalmenle explicadas por la segmenlación de la eslructura ocupacional y no por su mayor o menor calificación. Los dalos de la esIructura de remuneraciones de la población ocupada según el tipo de ocupación y pertenencia a una determinada estructura empresial, sugieren que el nivel educativo alcanzado por los trabajadores lendrla un menor peso explicativo, que le pertenecía a un determinado segmento laboral; 
como elemento causal de las diferencias observadas en la estructura de remuneraciones.

A pesar de que este aspecto debe ser más analizado, a través de encuestas directas que aporten dalos sobre el nivel educativo, la formación profesional y la historia ocupacional de los trabajadores de los diferentes tipos de empresas, creemos que la evidencia empírica invalida la concepción neo-clásica del funcionamiento del mercado de trabajo y en consecuencia invalida su explicación de la formación y diferenciación del salario.

Corno consecuencia de lo anterior las soluciones de política económica, en materia de pobreza y de reducción de las desigualdades de ingreso, que ofrece la leoría neo-clásica serian también parcialmenle invalidadas.

En efecto, si las desigualdades resultan de la segmentación, la solución al problema no podrá derivarse exclusivamente de la mejora de los niveles educativos de la población trabajadora, sino más bien de una transiormación de los mercados de Irabajo.

En este sentido, la altemativa sugerida por el enfoque de la segmentación en maleria política global de empleo consiste en el desarrollo de una politica a dos niveles; por una parte se debe estimular el crecimiento de los establecimientos del sector moderno y paralelamenle se debe promover la transformación productiva y organizacional de las pequenas empresas que tengan potencial de acumulación.

Para lograr esta expansión de los puestos de trabajo en el segmento laboral primario es convenienle considerar la propuesta desarrollada por PREALC, de "especializar la economia en un número reducido de sislemas integrados de producción que tienden a integrar verticalmenle el aparato productivo... (articulando) los sistemas en lorno a los seclores exportadores y los que producen bienes de consumo masivo."12

Una política de reorientación de la inversión como la anterior, no solo contribuiria a la maximización de la generación del empleo productivo, sino que también contribuiría a la superación de la restricción extema al crecimiento.

En relación a la transformación de la estructura ocupacional segmentada se deben desarrollar políticas selectivas de apoyo productivo al sector "informal". El criterio de selectividad viene determinado por dos faclores: en primer lugar, dada la heterogeneidad del campo de aclividades que engloba el sector "informal", no es conveniente estimular la proliferación desordenada de actividades que puedan conducir a una "terciarización prematura" de la economía. Por otra parte, dados los diferentes niveles de organización de los establecimientos y los espacios de 
mercado en que se insertan, solamente algunos de ellos cuentan realmente con potencial de transformación.

En este sentido las políticas de apoyo productivo para las actividades "informales" deben enfocarse a reforzar los vínculos dinámicos entre empresas del sector lormal y los pequenos establecimientos, con el objeto de levantar la restricción de demanda que pesa sobre estos últimos.

Las diferencias de enfoques en el análisis del mercado de trabajo son imporlantes por sus consecuencias en maleria de polltica económica; tal como se ha senalado anteriormente las políticas resultantes pueden incluso seguir direcciones opuestas.

Para el análisis de la segmentación de los mercados de trabajo lo importanle no es crear cualquier lipo de ocupación, debido a que tal como lo muesiran los resultados globales de este trabajo algunos "puestos de trabajo" solamente sirven para disfrazar el desempleo o generar ingresos de subsistencia en una lógica de "el dinero no me sobra y el trabajo lampoco".

Finalmente es necesario senalar que a pesar de las potencialidades que presentan las políticas de integración; el sub-empleo y el sector "informal" persistirán en tanto persisla el excedente estructural de mano de obra. Eslo significa que, a pesar de sus complementariedades, no deben confundirse las polliticas deslinadas a erradicar la pobreza con las políticas de empleo.

Mienlras subsista la pobreza crílica esta deberá ser entrentada con diferentes pollicas directas que involucren-a través del gasto públlco- transferencias financieras de los menos necesitados a los más necesilados y aumentos en el gasto de educación y salud para llegar seiectiva y prioritariamente a los grupos más pobres.

\section{Nolase}

- Una evaluación más completa del problema ocupacional y que constituye la bace de esto trabajo ha sido desarrollade en "Diagnóstico de le situación ocupacional" Carlos Brione\&/CENITEC Mayojunio 1988.

1. Los enfoques de la segmentación surgen como cribicas a las visiones neo-clácicas del mercado de trabajo, en particular a las lundadas en la teorla del capital humano que ulponen que las diferencias entre las remuneraciones $s e$ derivan de las diferencias en el capital humano (cualificaciones) adquirido. A origen de estas crlicas se encuentran Michael Piore y Peter B. Doeringer de la escuela "insulucionalista-estucturalista" norteamericana que plentean que los puestos de trabajo ee segmentan en función de les tecnologlas adoptadas por las empresas. Las tocnologlas intensives en capited orijhen procesos de aprendizeje especticos y tareas espectelizadoe con mecantsmos especlficos de movilidad ocupacional. Las tecnologles poco inteneivas en caplet -dade la menor división técnica del trabajo- se fundamenten en ocupedones poco expecta- 
lizadoe y poco calificados. Las inctustrias se reparten entre las dos lécnicas según el orado de estandarizeción del producto, unas veces por empresas y otras veces dentro de las mismas empresas. Los estudios de la segmentación en latinoamerica (llevados a cabo fundementalments por la PREALC) han enlatizado on la heterogeneidad esinctural que caracteriza las economlas de nuestros palses. Esta heterogeneidad trecultante de la eobrevivencia de formas de producción precapitalista- se refuerza con la exiotenda de un importante excedentes estuctural de mano de obra.

La combinación de embos factores tiende a segmentar la estructura ocupacional en doe cectores: cector "moderno o formal" y sector "informal".

En estro trabejo nosotros adoptamos un enloque eclectico y pragmático que considera los elementos de embos enfoques con el objeto de considerar la segmentación del secor formal y también captar la especificidad de la heterogeneidad ocupacional de las economlas sub-desartolladas. Como obras de relerencia pueden consultarse: M. Piore "Notes for a Theory of Labor Merket Stratification" traducido en Luis Toharia "El mercado de Trabajo: Teorlas y Aplieaciones" Alienza Universidad Textos, Madrid, 1983 pp. 193221 y PREALC "Sector Informal: Funcionamlento y pollticas" Santiago, Chile 1981.

2. No obstante este enorme aumento del desempleo abierto, la magnitud absoluta de las personas que se encuentran en situación de desempleo abierto podrla ser bastante menor. Un reciente estudio sobre la situación del empleo de acuerdo a la encuesta de hogares de 1885 - Gregory, P. "Análisis del Empleo dentro de la Encuesta de Hogares de El Salvedor USAID, Mayo 1987, - sehalaba que si se eliminaba del total de desempleados aquellas personas que no buseaban empleo activamente por razones de salud, oblloaciones tamilieres o asistencia a la escuela; la citra se reducirla sensiblemente, dieminuyendo la tase de desempleo a aproximadamente $10.4 \%$ del total de la población económicamente activa mayor de catorce años. En nuestra opinión, esta última cilra sera más realleta que la tasa global de desempleo (16.9\%) que arroja el Cuedro 1-A, sin embargo, dado que para los resultados de la encuesta de 1978 no se hablan limpiado las cilras de desempleados- de acuerdo a las razones de no haber buscado empleo actvamento- se ha preferido trabajar con las cilras globales de población desocupada para poder efectuar una comparación. De esta forma al comparar les cilras globales, aunque pudieren estar sobre estimados, obtendrlamos una idea aproximada del cambio experinentado en materia de desempleo de la fuerza de trabajo.

3. En el caso de las actividedes unipersonales de auto-oceupación no puede considerarse que participen en un mercado de trabajo pues no existirla ni separación de comprador y vendedor (de la huerza de trabajo) ni acto de compra. Para la fuerza de trabajo familiar no remunerada tampoco existirla un acto mercantil y por lo tanto lampoco padrla concebirsele formando perte del mercado de trabajo. Estas ocupaciones son las que $\infty$ múnmente se les conoce con el término de "inlomales" y la relación que guardan con los mercados de trabajo es la de "emortiguar-absorber" los desequilibrios "estructuraes" que se generan por la inadecuación de la demanda de trabajo asalariado y la oferla global de tuerza de trabajo.

4. Dado que por motivos de simplilicación se ha adoptado una segmentación por tarnaño de establecimiento ( $N^{n}$ de ocupados) el peso de los establecimientos agricolas va a ocultar la diversificación salarial.

Esto se debe fundamentaimente a dos factores: (a) las grandes empresas agrlcolas de exportación no tienen ningún "poder de mercado" pues son "tomadoras" de precios en el mercedo mundial; $y$ (b) las empresas no compiten por una mano de obra escasa. El resultado de la conjugación de estos dos fectores es que no se desarrolla un movimionto hacia la diterenciación de los salarios agrlcolas y éstos tienden a coincidir con lo6 salavios minimos legales. Si se adoptase además criterios adicionales relerentes al poder de mercado de las empresas, criterios de utilización de capital, etc.; podrla considerar80 a bob el empleo egricola como tormando parte del segmento "secundario". 
5. De acuerdo a Michael Piore "La búsqueda de instrumentos de pollica que remedien la dualidad del mercado de trabajo implica la mejora de actividades antidiscriminatorias, la reorganización del sector secundario para estabilizar la utilización de la mano de obra y la exploración de soluciones institucionales para lomentar el crecimiento en el seclor seaunderio de un tipo de empleo perecido al existente en el sector primario" Piore, M. "Unemployment and the Dual Labro Market" The Public Interest N0 38, 1975 Traducido en Luis Toheria, op. cit. pp. $307-320$

6. Souza, Paulo Renato. "Salario e Máo-de-Obra Excedente". Estudios CEBRAP No 25, 1978 Sao Paulo Brasil, p. B3. Es necesario aclarar que estas actividades se insertan en espacios de mercado que son delimitados y constantemente "remodelados" por el núcleo cepitalista de la economla.

7. Generalmente se trata de actividades de pequeña producción mercantil, comercio y/o servicios que con desarrollades por trabajadores independientes y por micro empresas de menos de cuatro ocupados con escaso desarrollo de relaciones salariales.

8. Adicionalmente puede considerarse que el sector inlormal urbano es alimentado por una parte de la mano de obra rural sobrante que deciden migrar a las ciudades. Sin embargo, es necesario señalar que no todo el flujo migratorio campo-ciudad se dirige hacia las actividades inlormales, ya que en buena medida, los trabajos no calificados del subsector de construcción pública se ha constivido en "puerta de entrada" de los migranlos masculinos a la ciudad.

9. En efecto la existencia de las ocupaciones autogeneradas permile absorber la parte "estruetural" del excedente de la olerta de trabajo- aquella parte de la fuerza laboral sobrante aún en condiciones de utilización normal o razonablemente plena de la capacidad instalada en el sector moderno- evitando de esta manera los desequilibrios en el mercedo laboral se refleja en un elevado desempleo abierto estructural. Por otra parte, cuando el uso de la capacidad instalada es menor que el normal y se genera un excedente "coyuntural", la autogeneración de ocupaciones puede actuar como un reductor del desempleo abierto eldico al presentar eltemativas de ocupación, a los desempleados más urgidos por obtener un ingreso, en lo que podrla denominarse actividades inlormales clelicas.

10. Dado que et Indice de precios al por mayor está calculado en base a $1978=100$, se ha ubilizado un lactor de variación de precios de 2.66; que mide la variación de precios al por mayor entre 1978 (100) y 1986 (266.1). La luente es CEPAL "Nolas para el estudio económico de América Latina y el Caribe, 1986 EI Salvador. LC/MEXL. 66 Nov. 1987.

11. El carácter oligopólico de la estructura manufacturera salvadoreña y la capacidad de formación de precios y de control de sus márgenes de ganancia ha sido evidenciada. Rivera, R. "La concentración manulacturera salvadoreña: Un intento de cuantificación", Tesis de Grado, Universidad Centroamerlcana "José Simeón Cañas" y Pérez, M. Y Contreras, L. "La lormación de Precios en la Manufactura Salvadoreña" Tesis de Grado, Universidad Centroamericana "José Simeón Cañas, 1967.

12. PREAlC "Deuda Social ¿Oué es, Cuánto es, Como se paga?, Santiago, Chile, 1988. p. 56. 


\section{Anexo 1}

\section{Calculo sub-ocupación por Ingreso}

El sub-empleo invisible se define generalmente como el conjunlo de los ocupados que, trabajando una jornada por lo menos - en términos de horas de trabajo-tienen un escaso ingreso y/o baja produclividad.

Para fines de cálculo se considera que los trabajadores que perciben una remuneración abajo de un ingreso normativo pueden considerarse como sub-utilizados en términos de su capacidad productiva potencial.

La elección de la norma es generalmente el salario mínimo legal; sin embargo cuando se trala de toda la población ocupada y no se conoce el salario minimo legal ponderado, puede elegirse el valor modal de la dislribucion de remuneraciones de la población asalariada. La elección de esta medida se basa en el supuesto de que la mayor concentración de

\begin{tabular}{|c|c|c|c|}
\hline $\begin{array}{l}\text { TAAMO D } \\
\text { RACION } \\
\text { (1985) }\end{array}$ & $\begin{array}{l}\text { E REMUNE- } \\
\text { UENSUAL }\end{array}$ & $\begin{array}{l}\text { EMPLEADOS ASALA- } \\
\text { RIADOS NO DOMES } \\
\text { TICOS }\end{array}$ & $\begin{array}{l}\text { DENSIDAD } \\
\text { DEL TRAMO }\end{array}$ \\
\hline 0 & 199 & 223,312 & $1,122.2$ \\
\hline 200 & 399 & 242,565 & $1,218.9$ \\
\hline 400 & 599 & 160,615 & 807.1 \\
\hline 600 & 799 & 96,824 & 486.5 \\
\hline 800 & - $\quad 999$ & 39,824 & 200.1 \\
\hline 1,000 & $-\quad 1,499$ & 22,593 & 45.3 \\
\hline 1,500 & - $\quad 1,999$ & 7,455 & 14.9 \\
\hline 2,000 & - Más & 6,386 & \\
\hline
\end{tabular}

FUENTE: Encuesla de Hogares 1985 (Cuadro B-19-1)

los trabajadores asalariados se dará alrededor del salario legal mínimo ponderado, de tal forma que el valor modal sería una buena aproximación al mismo.

Para ejemplificar el procedimiento vamos a utilizar el ano 1985. Considerando que los ingresos están uniformemenle distribuidos en los respectivos tramos, puede considerarse que el valor modal corresponderá al valor medio del intérvalo en donde se agrupe la mayor cantidad de trabajadores asalariados.

Como se observa la mayor densidad del tramo corresponde también a un agrupamiento mayor de trabajadores en ese tramo de ingresos. Por lo tanto se puede considerar como valor modal la media de ingresos de ese 
tramo ( $₫ 299.5$ ) que resulla de sumar los dos extremos y dividir entre dos.

Este mismo procedimiento se aplica a la distríbución de la población en 1978 obleniéndose un valor modal de 149.5 colones de 1978 .

Estos dos valores se consideraron como la norma de ingresos para segmentar los ocupados plenos y sub-ocupados por insuficiencla de ingresos.

\section{Anexo 2}

Cálculo de la estructura de remuneraclones de 1985

Para oblener la estructura de distribución de las remuneraciones del trabajo de 1985 en términos de 1978 se han realizado los siguientes pasos:

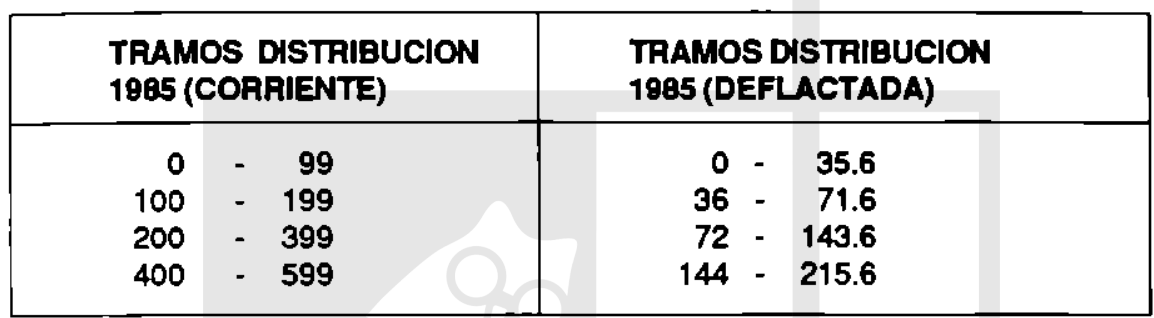

- Primeramente se ha considerado - de acuerdo a los datos del Indice de Precios al Consumidor - que el valor del colón entre octubre y diciembre de 1985 valla aproximadamente 0.36 colones de 1978 .

- Con este nuevo valor se procede a deflactar los extremos de las clases o tramos de la distribución de las remuneraciones de 1985.

- Para redistribuir la población de 1985 en una estructura comparable - tarnaño igual en las clases-a la de 1978, se procede a redistribuir cada tramo de 1985 como en el ejemplo siguienle:

Observamos que para reclasificar los primeros tramos de la distribución 1985 dellactada en el tramo 0 - 99 colones de 1978 no existe ningún problema, sin embargo para el tramo de ingreso de 200 a 399 colones de 1985 que deflactado se convierte en un tramo de 72 a 144.6 colones (1978) hay que reubicar esa población en dos tramos; unos en el 0 a 99 (1978) y otros en el Iramo 100 a 199 (1978). Para hacer esto se supone una distribución uniforme en cada tramo y se sacan los porcentajes del modo siguiente: 
- Se saca la diterencia entre el extremo mayor de la clase a la que se redistribuirá la población, para el caso 99 colones, y el extremo menor deflactado de la clase a redistribuir: $99-72=27$.

- Esta diferencia se divide entre el tamaño de la clase y cuya población Se redistribuye $143.6-72=71.6$

- Como es una distribución uniforme, el cocienle de las diferencias arrojan el porcentaje de la población del tramo a redislribuir que se encuentra abajo de los 99 colones (1978) de ingreso mensual.

$\frac{27}{71.6}=0.38 \%=38 \%$ de la población del tramo de 200 a 399 colones de ingreso (1985) perciben un ingreso menor de 99 colones de 1978 y pueden ser reubicadas en ese tramo de 0 a 99 colones. El resto $62 \%$ puede ser reubicado en el siguiente tramo (100 a 199 colones).

De esta forma se va reubicando la población ocupada de 1985 en tramos de ingreso de 1978 y se obtiene una eslruclura comparable entre los dos anos. 